\title{
Shortcomings and Inadequacies of Autonomy Argument for Euthanasia
}

\author{
Mohammad Manzoor Malik \\ Assistant Professor \\ Department of General Studies \\ Kulliyyah of Islamic Revealed Knowledge and Human Sciences \\ International Islamic University, Malaysia \\ E-mail: philomalik@iium.edu.my / philomalik@gmail.com
}

\begin{abstract}
Patient autonomy has a critical role in making decisions in medical practice and it is accepted by international conventions on health care and various national medical codes. However, pertaining to terminally ill patients, this right becomes very problematic in regards to end of life decisions. Utilitarian ethicists motivated by materialistic worldview and individualism have made patient autonomy based arguments for the permissibility of active euthanasia. An appraisal of pro-euthanasia arguments that include the best interest, golden rule, and autonomy is made in this paper. The best interest and golden rule arguments are based on subjective moral judgment thus failing the universalization test. The argument from autonomy is unconvincing because of the confounded autonomy of the terminally ill patients.
\end{abstract}

Key words: patient autonomy, golden rule, euthanasia, end of life decisions

Introduction: Patient autonomy has a critical role in making decisions in clinical practice. Universal Declaration on Bioethics and Human Rights adopted by acclamation on 19 October 2005 by the 33rd session of the General Conference of UNESCO in its Article 3 states: "Human dignity, human rights and fundamental freedoms are to be fully respected"; it further states in Article 5 "The autonomy of persons to make decisions, while taking responsibility for those decisions and respecting the autonomy of others, is to be respected. For persons who are not capable of exercising autonomy, special measures are to be taken to protect their rights and interests" ${ }^{1}$. These articles are well thought to affirm autonomy with precautions. Nevertheless, utilitarian ethicists take this right too far in defending right to active euthanasia on the grounds of autonomy. This study is made to demonstrate shortcomings of such arguments.

The contemporary intellectual discourse in support of euthanasia has potential consequences of leading to dehumanization which ought to be rejected. Euthanasia, by definition, is supposed to be for terminally ill persons; therefore, children, adults, and elderly people are subjects to it, however, elderly people are the most vulnerable. The harshness of euthanasia supporters could be understood from what Colorado governor Richard D. Lamm said in an address, which was reported in The New York Times, March 29, 1984, to the Colorado Health Lawyers Association: "Elderly people who are terminally ill have a duty to 
die and get out of the way" ${ }^{2}$. Similarly, Richard Fenigsen, who conducted research on Dutch elderly people, argues that a society which promotes euthanasia sends a message to the vulnerable that their lives are not valued. Instead, such a society tells them, "we wouldn't mind getting rid of you" 3 .

Apart from every sort of disciplinary perspective on the issue of euthanasia, the issue in its essential relation is practically connected with medicine. The issue of euthanasia has brought the medical profession in question. The traditional and common sense understanding of the profession is of life saving. However, the defenders of active euthanasia suggest redefining the profession not only as life saving, but also as life taking. Majority of the countries do not allow euthanasia as apparent from their national codes on health care, a position in line with The World Medical Association's Declaration on Euthanasia, adopted by the 38th World Medical Assembly, Madrid, Spain, in October 1987, as it states: "Euthanasia, that is the act of deliberately ending the life of a patient, even at the patient's own request or at the request of close relatives, is unethical. This does not prevent the physician from respecting the desire of a patient to allow the natural process of death to follow its course in the terminal phase of sickness" ${ }^{4}$.

However, due to growing individualism in contemporary societies with modern economical modalities there is a need of making a criticism of arguments for euthanasia by developing a philosophical and rationalistic critique of the arguments that argue by using the very cardinal concepts in which legal and ethical discourses are necessarily held such as autonomy, the best interest, public good, human rights, liberties, and duties.

Best Interests, Golden Rule and Autonomy Arguments: Utilitarian ethicists such as Peter Singer and Marvin Kohl have made arguments in favor of active euthanasia on the grounds of autonomy. A very elaborated and inclusive version of these arguments is developed by James Rachels from best interests and golden rule. Briefly, these arguments affirm that dying people should be free to choose euthanasia as a matter of personal liberty and autonomy.

Rachels starts from the utilitarian argument in favor of active euthanasia, however, he states that if an argument is based on the mercy alone on the utilitarian grounds, the argument will be faulty due to the Principle of Utility as a premise of the argument. Therefore, Rachels tries to avoid such a problem and comes up with an alternative argument, which is inspired, according to Rachels, by utilitarianism, but which avoids the difficulties of the pure utilitarian version of the argument, by not making the Principle of Utility a premise of the argument. Therefore, Rachels provides the following argument based on doing what is in everyone's best interests, and he claims that the argument is sound and proves that active euthanasia can be justified: 
1. If an action promotes the best interests of everyone concerned, and violates no one's rights, then that action is morally acceptable.

2. In at least some cases, active euthanasia promotes the best interests of everyone concerned and violates no one's rights.

3 Therefore, in at least some cases active euthanasia is morally acceptable ${ }^{5}$.

Rachels after presenting the above argument complements the argument by other arguments inspired by the golden rule. Rachels's golden rule argument is actually the reinforcement of his best interest argument. He states that Immanuel Kant incorporated the basic idea of the golden rule into his system of ethics. Rachels discusses the categorical imperative of Kant which says: act only according to that maxim by which you can at the same time will that it should become a universal law. Rachels elaborates on the principle: "that we should act only on rules that we are willing to have applied universally; that is, we should behave as we would be willing to have everyone behave" ${ }^{6}$. Rachels while taking the careful analysis of the principle states that the basic idea behind the golden rule is a good one. He points out the following principle:

the basic idea is that moral rules apply impartially to everyone alike; therefore, you cannot say that you are justified in treating someone else in a certain way unless you are willing to admit that that person would also be justified in treating you in that way if your positions were reversed ${ }^{7}$.

Rachels after going into explanatory details about the maxim ultimately tries to explain the meaning of the maxim and its relation to the case of euthanasia. Rachels relates the Golden Rule to active euthanasia by saying that if there are two choices to die: (1) to die quietly without pain by a fatal injection; and (2) to die of an affliction so painful that for several days before death "you would be reduced to howling like a dog, with your family standing by helplessly, trying to comfort you, but going through its own psychological hell". Rachels states that it is hard to believe that any sane person, when confronted by these possibilities, would choose to have a rule applied that would force upon him or her second option. And if we would not want such a rule, which excludes euthanasia, applied to us, then we should not apply such a rule to others ${ }^{8}$.

Rachels's main arguments in favor of active euthanasia are basically and essentially based on the consent of the terminally ill patient, that the justification of such practice is based on the free will and autonomy of the patient. Therefore, if a person autonomously chooses to end his or her life or have someone else assist him or her in doing so, then it is morally permissible. One should be free to do as one chooses as long as no harm is done to others. In supporting the position, Rachels develops a further argument for the legalization of active euthanasia based on the right to liberty. Briefly, this argument is that dying people should be free to choose euthanasia as a matter of personal liberty. The supporting argument frequently advanced in support of legalization of active voluntary euthanasia proceeds by way 
of analogy to the law of suicide. Rachels also supports his position by the same argument. The argument begins with the proposition that since it is not unlawful for a person to commit or attempt to commit suicide, the law, implicitly at least, recognizes the right of an individual to take his or her life. From this premise it is argued that if an individual does have the right to take his or her life, he or she should be able to seek the assistance of others in achieving this end ${ }^{9}$. Furthermore, Rachels's arguments such as the golden rule and the best interest argument are based on the same notion of autonomy that if a terminally ill patient chooses euthanasia as his best interest such a patient should be granted his wish.

Problems with Best Interests and Golden Rule Argument: There are three ways to argue against the Best Interests and Golden Rule Arguments and therefore rendering them unconvincing. They are: (1) the arguments are based on subjective moral judgment, failing the universalization test; (2) it may not be in my own best interests or in the best interests of others for me to die; and (3) the arguments are based on indefensible autonomy.

Firstly, the best interest and golden rule arguments are based on subjective moral judgment, therefore they fail the morally universalization test and become subject of partiality. The universalization test is crucial because Rachels himself accepts categorical imperative and so he is supposed to be having no objection if his moral position is subjected to such a test. If a person takes anything in his own interest, it does not guarantee that such an act would be desirable to other people. Put differently, people can dehumanize themselves and actually do so in active euthanasia by intentionally killing themselves or by others intentionally killing them. The golden rule argument fails due to its partiality and it fails the test of generality. First of all if active euthanasia is accepted because of its acceptance by some patients that does not make it generally acceptable. M. Cathleen Kaveny has suggestion also supports the above position as follows:

The most pressing challenge facing opponents of assisted suicide or voluntary euthanasia can be found in the faces of those who request such practices in order to put an end to their suffering. They are pointing to their own pain as a justification for carving out an exception to the general legal and moral rule against intentionally killing the innocent ${ }^{10}$.

The justification which some terminally ill patients give for euthanasia is in need of further scrutiny. The researches suggest that such approval of euthanasia is based mostly on the opinions of patients their decision power is clouded either by medication or depression. Hendin, Foley, \& White (1998) have referred to theses researches which scientifically describe the psychological conditions of terminally ill patients. The diagnosis of depression is particularly important since like other suicidal individuals, patients who desire an early death during a serious or terminal illness are usually suffering from a treatable depressive condition. Although pain and other factors, such as a lack of family support, may contribute to a patient's wish for death, depression is the most important factor. In fact, researchers have found 
depression to be the only factor that significantly predicts the wish for death. Two-thirds of patients requesting assisted suicide are depressed about the same percentage as those who attempt or commit suicide unaided. Hopelessness, the aspect of depression that helps distinguish depressed patients who are suicidal from those who are not, has been shown to play a similar role in predicting suicidal ideation in patients who are terminally ill ${ }^{11}$. In face of all these evidences, Rachels's case again fails the test of universalization which includes that the decision should be autonomous, but the researches show that the euthanasia willing patients are not rationally autonomous, they are either depressed or they are driven by other factors than reason.

Furthermore, it is important to elaborate on Kant's categorical imperative, which negates the conclusions of Rachels; "For Kant, our rational wills are the source of our moral duty, and it is therefore a kind of practical contradiction to suppose that the same will can permissibly destroy itself. Given the distinctive worth of an autonomous rational will, suicide is an attack on the very source of moral authority" ${ }^{12}$. Kant argued that taking one's own life was inconsistent with the notion of autonomy properly understood.

Secondly, it may not be in my own best interests or in the best interests of others for me to die. If I am willing to allow others to perform active euthanasia on me by the Golden Rule argument then I am willing to do so to them in return. This line of thought is mistaken. Rachels's point that once we are old what should be done to us could be objected by the similar questions. "As I lie dying, will I be offered humane care, will I be done in too soon by some expediency, or will I be subjected to terminal torture?" ${ }^{13}$. The researches show that the terminally ill patients do not ask for euthanasia in a way that could support any conception of Golden Rule for the permissibility of euthanasia. Those terminally ill patients who wish for euthanasia were found "affected by depression, feel unappreciated, and have significant need for help with the basics of living"; the report concludes:

A new study published in the November 15 Journal of the American Medical Association has found that most terminally ill patients would not choose physician-assisted suicide or euthanasia to end their lives. Interviews with 988 terminally ill adults and their primary caregivers revealed that around one in ten people seriously considered using physician-assisted suicide or euthanasia and that less than 6 percent had seriously discussed the possibility or taken steps to commit suicide. The researchers, led by Ezekiel J. Emanuel of the Department of Bioethics at the National Institutes of Health, also found that those who considered either option are affected by depression, feel unappreciated, and have significant need for help with the basics of living. The study's authors warn that doctors who receive requests for physicianassisted suicide or euthanasia should not consider patients to be definite about their decisions ${ }^{14}$.

The further objection to the argument based on autonomy is about autonomy itself and that is the consent of the patient on termination of life actively. The concerns involved are various such as how can it be sure that the person in condition which requires active euthanasia could have a free will; "there could be 
concern that the use of a pain killer in a dying individual could so cloud his conscious response that he might not in his dying moments be in a position to make decisions" ${ }^{15}$. The consent therefore received could not be accepted as reasonable and sound to substantiate such a decision. Paul R. McHugh argues, but when it comes to terminally ill patients, "outside forces" are likely to "overwhelm the self, rendering it vulnerable to unreflective impulses" ${ }^{16}$. Due to these factors, realization of patient's true autonomy becomes unattainable.

Conclusion: The best interest and golden rule arguments are based on subjective moral judgment, therefore they fail the morally universalization test and do not make a strong argument for the permissibility of euthanasia. Even approval of some terminally ill patients for active euthanasia is due to treatable depression and other factors rendering the approval to be a matter of compulsion instead of free autonomous wish. Regarding the relevance of Kant's categorical imperative to the arguments, Rachels's understanding of Kant turns out to be a misinterpretation because Kant argued that taking one's own life was inconsistent with the notion of autonomy properly understood. Finally, the argument from autonomy fails to claim the sufficient support to substantiate a pro-position for the approval of active euthanasia because autonomy of terminally ill patients is problematic in a way that it seems such patients are not autonomous but influenced by various factors rendering their discretion unreliable.

\section{References:}

1. Universal Declaration on Bioethics and Human Rights (Oct 19, 2005).

2. Kearl MC. Endings: A sociology of death and dying: Oxford University Press 1989.

3. Fenigsen R. A case against Dutch euthanasia. The Hastings Center Report. 1989;19(1).

4.World Medical Association, Resolution on euthanasia. 2005; Available from: www.wma.net/e/policy/e13b.htm.

5. Rachels J. More impertinent distinctions and a defense of active euthanasia. In: Norcross A, Steinbock B, editors. Killing and letting die 2nd ed. New York, USA: Fordham University Press.

6. Ibid.

7. Ibid.

8. Ibid.

9. Rachels J. Barney Clark's key. The Hastings Center Report. 1983;13(2):17-9.

10. Kaveny MC. Assisted suicide, euthanasia and the law. Theological studies. 1997;58(1).

11. Hendin H, Foley K, White M. Physician-assisted suicide: Reflections on Oregon's first case. Issues in Law \& Medicine. 1998;14(3):243-70. And Hendin H, Foley K, White M. Oregon Death with Dignity Act. Issues in Law \& Medicine. 1998;14(3):243-70.

12. Cholbi M. Suicide. 2004; Available from: http://plato.stanford.edu/entries/suicide/.

13. Vaux KL. Debbie's dying mercy killing and the good death. In: Baird RM, Rosenbaum SE, editors. Euthanasia: The moral issues Buffalo, New York. 
14. Emanuel E. Assisted suicide largely shunned. The Christian Century. 2000;117:34.

15. Koop CE. The right to die: The moral dilemmas. In: Baird RM, Rosenbaum SE, editors. Euthanasia: The moral issues Buffalo, New York: Prometheus Books.

16. McHugh PR. On death and dying [Review of the article Dying made easy] Commentary. 1999; 107(5).

Conflict of Interest: This research article is solely written and researched by the author, Mohammad Manzoor Malik. No research grant or funding was obtained from any institution that may deserve any acknowledgement. 